\title{
Tumor Size and Age Predict the Risk of Malignancy in Hürthle Cell Neoplasm of the Thyroid and Can Therefore Guide the Extent of Initial Thyroid Surgery
}

\author{
Tae Hyuk Kim, ${ }^{1}$ Jung Ah Lim, ${ }^{1}$ Hwa Young Ahn, ${ }^{1,2}$ Eun Kyung Lee, ${ }^{1}$ Hye Sook Min, ${ }^{3}$ Kyung Won Kim, ${ }^{4}$ \\ Yun-Hee Choi, ${ }^{5}$ Young Joo Park, ${ }^{1,2}$ Do Joon Park, ${ }^{1}$ Kwang Hyun Kim, ${ }^{6}$ Yeo Kyu Youn, ${ }^{7}$ and Bo Youn Cho
}

Background: The majority of patients having a diagnosis of Hürthle cell neoplasm (HCN) on fine-needle aspiration (FNA) of a thyroid nodule have a diagnostic thyroid lobectomy to make the final diagnosis. If the nodule is malignant, they require a completion thyroidectomy. The objective of this study was to devise a simple clinical scheme capable of predicting malignancy in patients with cytologic diagnosis of $\mathrm{HCN}$ and, therefore, guide the extent of initial thyroid surgery.

Methods: A total of 57 patients who underwent thyroid surgery after an FNA diagnosis of HCN were retrospectively studied. The patients were examined for clinical features, preoperative imaging studies, and pathology reports. The risk of malignancy was calculated using a multiple logistic regression model.

Results: The overall rate of malignancy in patients with HCN was $46 \%(26 / 57)$. The predictors of malignancy based on multiple logistic regression analysis were tumor size $>1.5 \mathrm{~cm}$ (odds ratio [95\% confidence interval] $=8.0[1.9-33.4]$ ) and patient age $>45$ years (odds ratio [95\% confidence interval] $=2.3[0.6-8.6]$ ). In patients with nodules larger than $1.5 \mathrm{~cm}$, the predicted probability of malignancy was greater in patients over 45 years than in younger patients ( $65 \%$ for $>45$ years vs. $44 \%$ for $\leq 45$ years). In patients with a nodule $1.5 \mathrm{~cm}$ or less, the probability of malignancy was relatively low and not significantly different between the two age categories $(18 \%$ for $>45$ years vs. $10 \%$ for $\leq 45$ years).

Conclusions: This study suggests that tumor size and age can be integrated into decision making for patients with an FNA diagnosis of HCN to facilitate patient selection for surgical referral and, particularly, to determine in which patients a thyroidectomy rather than a lobectomy should be the initial surgery.

\section{Introduction}

$\mathbf{H}$ ÜRTHLE CELLS, ALSO known as oxyphil cells or oncocytes, are large, polygonal cells with an eosinophilic granular cytoplasm due to the presence of abundant mitochondria. Hürthle cells can be present in both benign and malignant lesions of the thyroid, including Hürthle cell adenomas (HCAs), Hürthle cell carcinomas (HCCs), hyperplastic nodules in chronic lymphocytic thyroiditis, adenomatous/ multinodular goiters with Hürthle cell metaplasia, and other differentiated thyroid carcinomas (1).

Hürthle cell neoplasm (HCN) is an encapsulated tumor consisting of predominantly (over 75\%) Hürthle cells. Since
HCC usually appears cytologically identical to HCA, fineneedle aspiration (FNA) is unable to differentiate between malignant and benign HCN. Therefore, FNA diagnosis of $\mathrm{HCN}$ is classified as indeterminate for malignancy. HCC represents $\sim 3 \%$ of differentiated thyroid carcinomas with clinically aggressive behavior compared with papillary and follicular carcinoma, and it has a relatively high prevalence of metastases, a lower survival rate, and decreased avidity for ${ }^{131} \mathrm{I}(2-4)$. To date, there are no absolute preoperative or intraoperative methods that can reliably differentiate between benign and malignant $\mathrm{HCN}$ (5). Given the aggressiveness of $\mathrm{HCC}$, a majority of cases diagnosed as $\mathrm{HCN}$ undergo diagnostic thyroid lobectomy, and in cases of HCC, clinicians

\footnotetext{
${ }^{1}$ Department of Internal Medicine, Seoul National University College of Medicine, Seoul, Korea.

${ }^{2}$ Department of Internal Medicine, Seoul National University Bundang Hospital, Seongnam, Korea.

${ }^{3}$ Department of Pathology, ${ }^{4}$ Healthcare System Gangnam Center, and ${ }^{5}$ Medical Research Collaborating Center, Seoul National University Hospital, Seoul, Korea.

Departments of ${ }^{6}$ Otorhinolaryngology-Head and Neck Surgery and ${ }^{7}$ Surgery, Seoul National University College of Medicine, Seoul, Korea.
} 
prefer to perform a complete total thyroidectomy (6). A few studies have reported on clinical predictors of malignancy in patients with an FNA diagnosis of $\mathrm{HCN}$. Clinical features such as male gender, old age, large tumor size and some FNA features of small cell dysplasia, large cell dysplasia, and nuclear crowding have been reported to be associated with malignant nodules (7-11). However, these findings have not been confirmed by other investigators (12). Disagreement on the usefulness of specific features is partly due to the small number of cases and inconsistent cytologic criteria of $\mathrm{HCN}$ among studies.

The main drawback of routine diagnostic thyroid lobectomy in patients with HCN by FNA is that many patients need subsequent completion thyroidectomy in case of malignancy. Many experts emphasize that FNA results should be interpreted in light of clinical features. Likewise, the systematic combination of clinical features with an FNA result has been shown to increase the accuracy of FNA biopsy results alone (13). The objective of this study was to devise a simple clinical scheme capable of predicting malignancy in patients with an FNA diagnosis of HCN.

\section{Materials and Methods}

\section{Case selection and evaluation}

After approval was obtained from the Institutional Review Board at Seoul National University Hospital, a retrospective computerized search was carried out of all thyroid FNAs performed at the Seoul National University Hospital between March 1997 and November 2008. A group of 82 patients with an FNA diagnosis of $\mathrm{HCN}$ was identified. Among them, 57 $(70 \%)$ received subsequent surgical excision, and surgical histopathological diagnoses were identified.

The patients' clinical features including age, gender, preoperative serum thyroid-stimulating hormone (TSH) level, and thyroid hormone therapy were reviewed. Preoperative imaging studies were also analyzed, including ultrasound or computed tomography, thyroid scintigraphy, FNA reports, and final pathology reports. The size of the nodule was measured as the longitudinal diameter from preoperative ultrasound or computed tomography.

The normal range for the highly sensitive serum TSH assay used was $0.4-4.1 \mathrm{mIU} / \mathrm{L}$. Patients with a serum TSH level $>4.1 \mathrm{mIU} / \mathrm{L}$ or on preoperative thyroid-hormone-replacement therapy were considered hypothyroid cases, and patients with a TSH level $<0.4 \mathrm{mIU} / \mathrm{L}$ were considered hyperthyroid cases. Patients with a normal serum TSH level who were not receiving thyroid-hormone replacement therapy were categorized as euthyroid.

Thyroid FNAs were performed by an endocrinologist or radiologist. Cytologic criteria used for the diagnosis of $\mathrm{HCN}$ included a cellular specimen, a monotonous population of oncocytic/Hürthle cells ( $>75 \%$ of the specimen) associated with little or no background colloid, and the absence of nuclear features of papillary thyroid carcinoma. Specimens interpreted as suspicious for adenomatous goiter with Hürthle cell metaplasia or with coexisting background chronic lymphocytic thyroiditis were excluded $(7,14)$.

Pathology reports were reviewed to identify the pathology of the primary (index) nodule. Incidentally, detected cancer was not included in this study. HCA was defined as an encapsulated tumor consisting exclusively or predominantly of
Hürthle cells. HCC was defined as HCN with full thickness invasion through the capsule or vascular invasion or metastatic disease $(11,15)$.

\section{Statistical analysis}

Clinical and radiologic features were compared between patients with benign and malignant histology at the time of thyroidectomy. Data for age were expressed as means \pm standard deviation. Data for nodule size that were not normally distributed were presented as medians and ranges. For four cases, size data from preoperative imaging were not available. Accordingly, they were considered as a missing value. Student's $t$-test and the Mann-Whitney $U$ test were used to compare the mean values of continuous data. For a univariate analysis, the Fisher's exact and chi-square tests were used to determine the statistical significance of differences in categorical data observed between groups. The linear trends of the effect of nodule size and patient age on the rate of malignancy were separately tested using logistic regression models.

We used logistic regression to construct receiver operating characteristic (ROC) curves as well as to estimate the area under the curves of nodule size and age to assess the ability of these clinical parameters to predict malignancy. ROC analysis allowed the determination of the optimal cutoff for nodule size and age to maximize accuracy (16-18). The diagnostic accuracy of nodule size and the age parameters for predicting malignancy were determined using the area under the ROC curve (Fig. 2). For multiple analyses, a logistic regression model was fit to the data by adjusting for all significant covariates identified from the univariate analysis. The associations between factors of interest and malignancy risk were estimated as odds ratios (ORs) and 95\% confidence intervals (CIs). The Hosmer-Lemeshow goodness-of-fit statistic $(p>0.05)$ was used to evaluate model fit (19).

We classified the patients into four groups according to nodule size and age cutoff to maximize the clinical availability of the prediction model. We used the model to calculate the predicted probability of malignancy in each patient group. All statistical analyses were performed using SPSS for Windows, version 17.0 (SPSS, Chicago, IL).

\section{Results}

\section{Patient diagnoses and clinical characteristics}

In this study of 82 patients with an FNA diagnosis of $\mathrm{HCN}$, $57(70 \%)$ received subsequent surgical excision and 25 patients did not. There were no significant differences in terms of age, gender, nodule size, or preoperative radiologic features between patients undergoing surgical excision and those who did not (data not shown). For the majority of patients, the reason for not proceeding to surgical removal was listed in the medical record as patient preference. From those 25 cases who did not undergo surgery, nodule sizes of 10 cases were followed up in outpatient clinics (mean follow-up duration of 17.2 months). Nodules in three cases decreased over $20 \%$ in the main cystic portion (21 months), nodules in two cases increased over $20 \%$ (mean follow-up duration of 23.5 months), and nodules in five cases remained unchanged (mean follow-up duration of 12.4 months). No clinically aggressive lesions including metastases were reported. 
After undergoing thyroid resection, 26 patients (46\%) received a final diagnosis of malignancy. There were 10 HCC (39\%), 9 papillary carcinomas (34\%), and 7 follicular carcinomas (27\%). The benign histological diagnoses included 19 HCA $(61 \%), 9$ benign thyroid nodules $(29 \%), 2$ follicular adenoma $(7 \%)$, and 1 case of chronic lymphocytic thyroiditis $(3 \%)$.

The clinical characteristics were compared between benign and malignant nodules and are presented in Table 1. Patients with malignant nodules were significantly older than those without nodules. The relationship between age and rate of malignancy is displayed in Figure 1A. Although older patients were more likely to have a malignant thyroid nodule, the linear relationship across the category of age was not evident after adjustment for nodule size ( $p$ for trend $=0.078$ ). The majority of patients were women $(79 \%)$, and there were no differences in gender between the two groups.

The nodule sizes ranged from 0.8 to $6.7 \mathrm{~cm}$ (median $1.9 \mathrm{~cm}$ ). The nodule size was significantly greater in patients with a malignant nodule compared with those with a benign nodule $(p=0.01)$. A significant positive linear relationship was documented between the rate of malignancy and nodule size ( $p$ for trend $=0.016$, Fig. 1B). The prevalence of malignancy was $0 \%(0 / 6)$ in nodules $\leq 1.0 \mathrm{~cm}$ and $20 \%(3 / 15)$ in nodules measuring $1.0-1.5 \mathrm{~cm}$. The rate of malignancy in larger nodules measuring 1.6-2.0,2.1-2.5, and $>2.5 \mathrm{~cm}$ was increased to $67 \%(6 / 9), 50 \%(4 / 8)$, and $60 \%(9 / 15)$, respectively.

Other clinical and radiologic features, such as thyroid nodules detected by health care workers, thyroid function, hardness of the nodule to palpation, and the scintigraphic coldness of nodule, were not associated with malignancy. Certain sonographic features, such as hypo-echogenicity, ir-

Table 1. Clinical Characteristics of 57 Patients with a Fine-Needle Aspiration Diagnosis of Hürthle Cell Neoplasm

\begin{tabular}{|c|c|c|c|}
\hline & $\begin{array}{l}\text { Benign } \\
(\mathrm{n}=31)\end{array}$ & $\begin{array}{l}\text { Malignant } \\
(\mathrm{n}=26)\end{array}$ & $\mathrm{p}$-Value \\
\hline \multicolumn{4}{|l|}{ Age, year } \\
\hline Mean \pm SD & $47 \pm 12$ & $54 \pm 13$ & 0.046 \\
\hline \multicolumn{4}{|l|}{ Gender } \\
\hline Female, $n(\%)$ & $25(81)$ & $20(77)$ & 0.73 \\
\hline \multicolumn{4}{|l|}{ Nodule size, $\mathrm{cm}$} \\
\hline Median & 1.5 & 2.2 & 0.01 \\
\hline Range & $0.8-4.8$ & $1.1-6.7$ & \\
\hline \multicolumn{4}{|l|}{ Detected by } \\
\hline Doctor, $n(\%)$ & 7 (23) & $3(12)$ & 0.32 \\
\hline Patient, $n(\%)$ & $23(77)$ & $22(88)$ & \\
\hline \multicolumn{4}{|l|}{ Thyroid function, $n(\%)$} \\
\hline Hyperthyroid & $3(11)$ & $4(17)$ & 0.42 \\
\hline Euthyroid & $21(78)$ & $14(61)$ & \\
\hline Hyperthyroid & $3(11)$ & $5(22)$ & \\
\hline $\begin{array}{l}\text { Hard nodule to } \\
\quad \text { palpation, } n(\%)\end{array}$ & $11(55)$ & $8(67)$ & 0.71 \\
\hline \multicolumn{4}{|c|}{ Sonographic finding, $n(\%)$} \\
\hline Hypo-echogenicity & $12(67)$ & $7(58)$ & 0.71 \\
\hline Irregular margin & $0(0)$ & $2(20)$ & 0.13 \\
\hline Calcified nodule & $0(0)$ & $3(17)$ & 0.08 \\
\hline $\begin{array}{l}\text { Scintigraphically } \\
\quad \text { cold nodule, } n(\%)\end{array}$ & $8(89)$ & $8(100)$ & 1.00 \\
\hline
\end{tabular}

$\mathrm{SD}$, standard deviation. regular margins, and the presence of calcification, were suggestive of malignancy in thyroid nodules (20). However, these sonographic findings were not significantly different between malignant and benign Hürthle cell nodules.

\section{ROC curve analysis}

We chose to derive a predictor for malignancy based on nodule size and patient age. The rate of malignancy was significantly higher when the nodule was larger than $1.5 \mathrm{~cm}$ $(65 \%$ vs. $20 \%, p=0.001)$. Older age ( $>45$ years) also tended to be more common in cases of malignant nodule, although it did not reach statistical significance ( $54 \%$ vs. $30 \%, p=0.08$ ). The cutoff value of age over 45 years was $77 \%$ sensitive and $45 \%$ specific for predicting malignancy (Fig. 2). Similarly, a nodule size larger than $1.5 \mathrm{~cm}$ was $86 \%$ sensitive and $58 \%$ specific. The group of patients older than 45 years with a thyroid nodule larger than $1.5 \mathrm{~cm}$ had $68 \%$ sensitivity and $74 \%$ specificity. Treating them as continuous variables, the

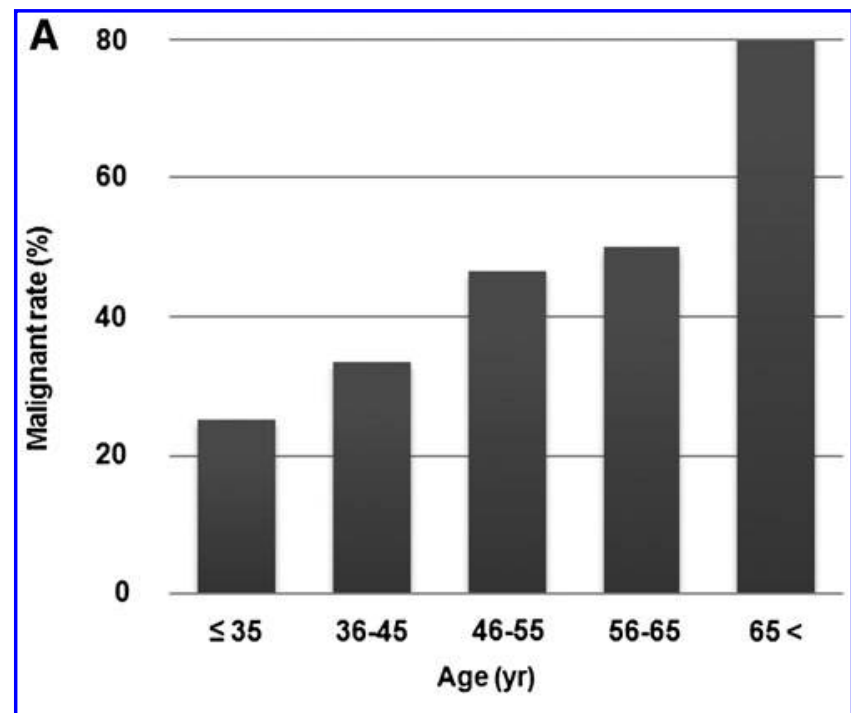

B 80

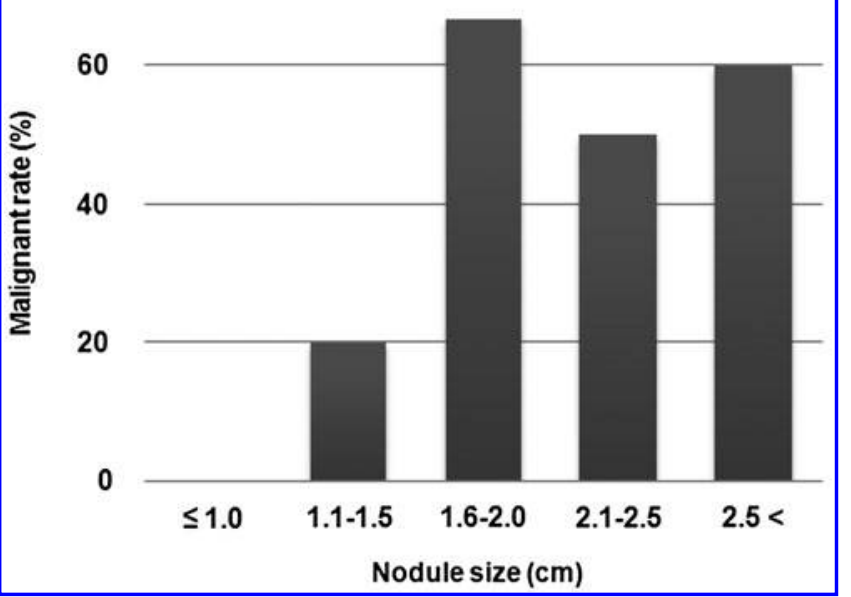

FIG. 1. In patients with Hürthle cell neoplasm, the rate of malignancy increased with increasing patient age (A) and nodule size (B). 


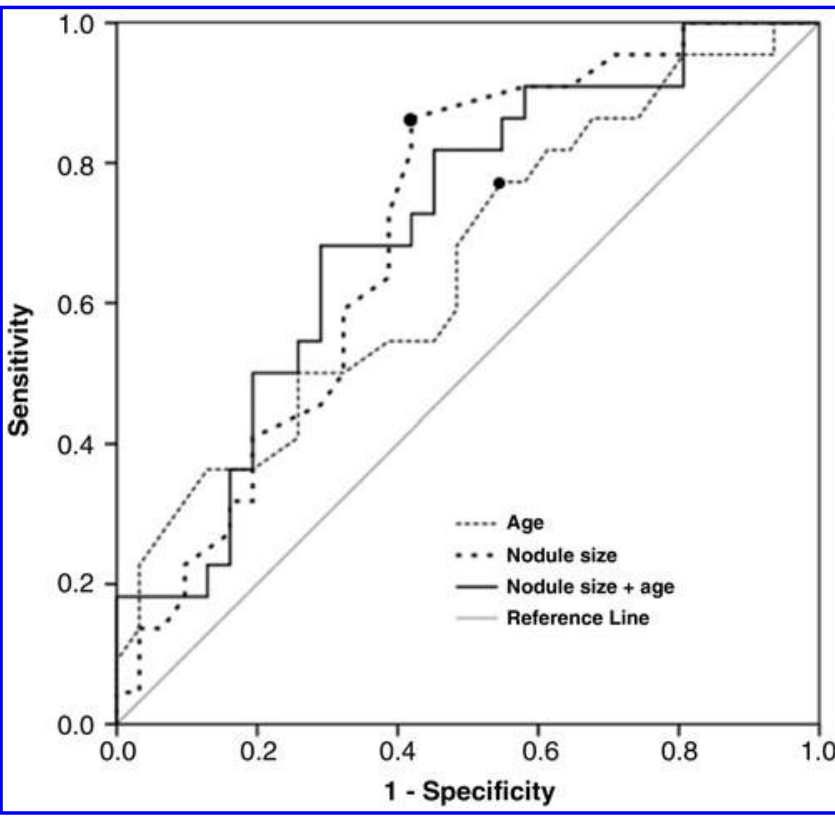

FIG. 2. Receiver operating characteristic (ROC) curves in 57 patients with a fine-needle aspiration diagnosis of Hürthle cell neoplasm. The model applied includes nodule size plus age (solid line), nodule size alone (dotted line), and age alone (broken line) for the detection of malignant nodules. An age older than 45 years is $77 \%$ sensitive and $45 \%$ specific for predicting malignancy; a nodule size larger than $1.5 \mathrm{~cm}$ is $86 \%$ sensitive and $58 \%$ specific.

areas under the ROC curves for a regression model using age and nodule size are 0.653 (95\% CI 0.503-0.804, $p=0.059)$ and 0.707 (95\% CI 0.567-0.846, $p=0.011$ ), respectively. Combining nodule size and age, the area under the ROC curve increased to $0.710(95 \%$ CI $0.570-0.850, p=0.010)$.

\section{Risk assessment by a multiple logistic regression model}

We conducted multiple logistic regression analysis by including nodule size and patient age, which were identified as predictors of malignancy based on univariate analysis. Nodule size and age were analyzed both as continuous and as categorical variables (Table 2). The predictors of malignancy included nodule size $>1.5 \mathrm{~cm} \quad(\mathrm{OR}=8.00,95 \% \mathrm{CI}=1.92$ $33.37, p=0.004)$ and patient age $>45$ years $(\mathrm{OR}=2.25,95 \%$ $\mathrm{CI}=0.59-8.61, p=0.238$ ). Nodule size remained a significant independent predictor. After adjustment for nodule size, the association with age was attenuated $(p=0.238$ for age $>45$ years). Age, a statistically not significant predictor, was included in the prediction model due to the adjusted effect of age $(\mathrm{OR}=2.25$ for age $>45$ years) being clinically meaningful, and the number of study participants was not sufficient to achieve statistical power due to the rarity of HCN. Hence, the prediction model consisted of age and nodule size. We did not factor irregular margins and calcification into the prediction model due to missing data regarding sonographic findings. The $p$-value of the Hosmer-Lemeshow goodness-of-fit test was 1.00, and the relationship between nodule size and age was not statistically significant.
Table 2. Results of Multiple Logistic Regression Analysis for Predictors of Malignancy

\begin{tabular}{|c|c|c|}
\hline & OR $(95 \% C I)$ & $\mathrm{p}$-Value \\
\hline Nodule size, $\mathrm{cm}^{\mathrm{a}}$ & $1.70(0.99-2.94)^{\mathrm{b}}$ & 0.056 \\
\hline Nodule size $>1.5$ vs. $\leq 1.5 \mathrm{~cm}^{\mathrm{c}}$ & $8.00(1.92-33.37)$ & 0.004 \\
\hline Age, year ${ }^{a}$ & $\begin{array}{l}1.05(1.00-1.10)^{\mathrm{b}} \\
1.57(0.95-2.59)^{\mathrm{d}}\end{array}$ & 0.076 \\
\hline Age $>45$ vs. $\leq 45$ years $^{c}$ & $2.25(0.59-8.61)$ & 0.238 \\
\hline
\end{tabular}

${ }^{\mathrm{a}}$ Hosmer-Lemeshow goodness-of-fit test: $p=0.34$ (chi-square statistics $=9.04 ; \mathrm{df}=8$ ).

${ }^{\mathrm{b}}$ Estimated OR and $95 \%$ CIs for a 1-unit increase

${ }^{c}$ Hosmer-Lemeshow goodness-of-fit test: $p=1.00$ (chi-square statistics $=0.01 ; \mathrm{df}=2$ ).

${ }^{\mathrm{d}}$ Estimated OR and $95 \%$ CIs for a 10 -unit increase

$\mathrm{CI}$, confidence interval; OR, odds ratio.

Finally, we classified the patients into four risk strata according to nodule size and age cutoff to maximize the clinical availability of the prediction model. The model provided moderate discrimination between patients with benign versus malignant nodules (area under the ROC curve $=0.760,95 \%$ $\mathrm{CI}=0.629-0.891$ ). The predicted probability of each group is presented in Figure 3. In patients with nodules larger than $1.5 \mathrm{~cm}$, the predicted probability of malignancy was greater in patients aged over 45 years than in younger patients $(65 \%$ for $>45$ years vs. $44 \%$ for $\leq 45$ years). In patients with nodule size $1.5 \mathrm{~cm}$ or less, the probability was relatively low and not different between the age categories $(18 \%$ for $>45$ years vs. $10 \%$ for $\leq 45$ years).

\section{Discussion}

HCNs are rare thyroid tumors and are classified as subtypes of follicular-derived tumors, composed of oncocytic/ Hürthle cells (21). It is difficult for clinicians to classify this tumor as malignant or benign before surgery. In this study, we devised a simple clinical classification scheme by integrating clinical features to estimate the risk of malignancy in patients with HCN.

Surgical follow up was conducted in $70 \%(57 / 82)$ of patients cytologically diagnosed with HCN. Among these patients, $46 \%(26 / 57)$ were classified as having a malignant nodule. The malignancy rate in the present study is higher than that of previous reports of surgical follow up of HCN on

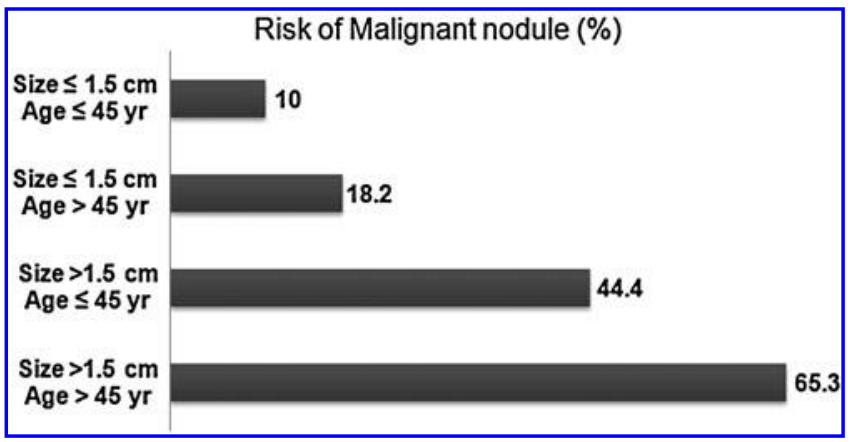

FIG. 3. Results of multiple analysis showing the predicted probability of malignancy in Hürthle cell neoplasm for each group of patients based on nodule size and age. 
FNA $(16 \%-45 \%)(7-10,12)$. Inconsistent cytologic criteria of $\mathrm{HCN}$ among studies might account for the wide range in the rate. The inclusion of a significant number of patients with benign thyroid disease can markedly alter the prevalence of malignancy. Studies that include multiple Hürthle cell nodules found in the context of goiter or chronic lymphocytic thyroiditis indicate that $>80 \%$ of HCNs are benign $(1,12)$. In this study, to rule out benign lesions with Hürthle cell changes, patients with FNA findings of an adenomatous nodule or chronic lymphocytic thyroiditis were excluded (14). Eight patients were excluded due to a cytologic diagnosis of an adenomatous goiter with Hürthle cell metaplasia; their surgical pathology follow up showed two cases (25\%) of malignant nodules. Selection bias involved in referring patients for surgery might affect the malignancy rate. However, there were no statistically significant differences in terms of age, gender, nodule size, and sonographic findings between patients who underwent surgery and those who did not.

The most significant predictor of malignancy in this study was nodule size. We found a strong positive correlation between nodule size and the rate of malignancy. HCCs have been reported to be generally larger than HCAs (12), and several authors have reported an association between tumor size and malignancy rate in $\operatorname{HCN}(7,22,23)$. In a study of 109 FNA cases of HCN, Giorgadze et al. (7) reported that the risk of malignancy was greater in nodules larger than $2 \mathrm{~cm}$, whereas some others have not found this association to be significant (12). In this study, patients with a larger nodule size $(>1.5 \mathrm{~cm})$ had a higher incidence of malignancy compared with patients with smaller nodules.

Aspirates from papillary thyroid carcinoma can demonstrate a predominance of oncocytic follicular cells $(1,24)$ and, accordingly, those cases can be misdiagnosed as HCN. Since papillary carcinoma can be as small as a few millimeters, the inclusion of papillary thyroid carcinoma in a group can change the average tumor size. In a study of 57 cases of $\mathrm{HCN}$ that reported no papillary carcinoma in the final pathology, the mean tumor size in malignant cases was $5.1 \mathrm{~cm}$ (9). In our study, nine cases ( $34 \%$ of malignant cases) were diagnosed as papillary carcinoma after pathology follow up, similar to the $23 \%-50 \%$ rate seen in previous studies $(7,8,25)$. Surgical specimens of those cases were compatible with oncocytic variants of papillary carcinoma. The mean nodule size of patients with papillary carcinoma in the final pathology was smaller than that of patients with HCC or follicular carcinoma, although statistically insignificant ( $2.0 \mathrm{vs} .2 .9 \mathrm{~cm})$.

It has also been shown that thyroid malignancy, especially the Hürthle cell type, is more common in older patients $(8,22)$. A previous study reported that patients older than 40 years with a diagnosis of HCN had a higher rate of malignancy than those $<40$ years (7), although others have not found the same association $(23,26)$. In our study, patients older than 45 years had a higher rate of malignancy than those $\leq 45$ years. Interestingly, among 13 patients older than 60 years, the malignancy rate rose to $69 \%$, a finding which suggests that age is a more significant risk factor for malignancy at the extremes of age (27).

So far, only a few studies have attempted to integrate multiple clinical features and FNA results in an evaluation of thyroid nodules diagnosed as follicular neoplasm $(27,28)$, and none have been in patients with HCN. In a study of patients with an FNA diagnosis of follicular neoplasm, Tuttle et al. (27) integrated the clinical features of gender, nodule size, and characteristics of thyroid gland by palpation and reported the post-test probability of malignancy to be $3 \%-77 \%$. In the present study, when we combined the information of nodule size and age, the discriminative power of the final model evaluated by the ROC curve showed an area under the curve of 0.760 , making it a reasonable diagnostic test for predicting malignancy. This study makes use of the widely accepted multiple logistic regression model as a means to combine two clinical variables into a rapid estimation of the probability of malignancy for a specific patient.

This simple clinical scheme could also be useful for determining the extent of initial thyroidectomy. Patients with a small nodule $(\leq 1.5 \mathrm{~cm})$ have a relatively low risk of malignancy $(<20 \%)$, and diagnostic lobectomy would be enough to rule out malignancy in these patients. In contrast, diagnostic surgical resection should be recommended to patients with a larger nodule $(>1.5 \mathrm{~cm})$. Specifically, the predicted probability reached $65 \%$ in patients older than 45 years with a large tumor size over $1.5 \mathrm{~cm}$. For these patients, consideration should be given for an initial total thyroidectomy to avoid additional surgery.

This study has some limitations that are important to note. The cutoff values of age and nodule size in the prediction model were determined based on ROC analysis. Such an outcome-based method was known to inflate type I error (29). However, the goal of this study was not to verify significant factors but rather to estimate the probability of malignant $\mathrm{HCN}$. Thus, the prediction using the cutoff values from ROC analysis may increase the prediction accuracy, although the $p$-values provided in Table 2 may be inflated. Also, the optimal cutoff values could not be validated in this study due to the small amount of data.

In conclusion, two simple clinical features, nodule size and age, can be combined with an FNA diagnosis of HCN to estimate the probability of malignancy. This simple risk stratification scheme may help clinicians make better decisions for surgical referral and, particularly, for determination of the extent of initial thyroid surgery.

\section{Disclosure Statement}

The authors declare that no competing financial interests exist.

\section{References}

1. Montone KT, Baloch ZW, LiVolsi VA 2008 The thyroid Hürthle (oncocytic) cell and its associated pathologic conditions: a surgical pathology and cytopathology review. Arch Pathol Lab Med 132:1241-1250.

2. Lopez-Penabad L, Chiu AC, Hoff AO, Schultz P, Gaztambide S, Ordonez NG, Sherman SI 2003 Prognostic factors in patients with Hürthle cell neoplasms of the thyroid. Cancer 97:1186-1194.

3. McLeod MK, Thompson NW 1990 Hürthle cell neoplasms of the thyroid. Otolaryngol Clin North Am 23:441-452.

4. Watson RG, Brennan MD, Goellner JR, van Heerden JA, McConahey WM, Taylor WF 1984 Invasive Hürthle cell carcinoma of the thyroid: natural history and management. Mayo Clin Proc 59:851-855.

5. Baloch ZW, LiVolsi VA 1999 Oncocytic lesions of the neuroendocrine system. Semin Diagn Pathol 16:190-199. 
6. Hundahl SA, Cady B, Cunningham MP, Mazzaferri E, McKee RF, Rosai J, Shah JP, Fremgen AM, Stewart AK, Holzer S 2000 Initial results from a prospective cohort study of 5583 cases of thyroid carcinoma treated in the united states during 1996. U.S. and German Thyroid Cancer Study Group. An American College of Surgeons Commission on Cancer Patient Care Evaluation study. Cancer 89:202-217.

7. Giorgadze T, Rossi ED, Fadda G, Gupta PK, Livolsi VA, Baloch Z 2004 Does the fine-needle aspiration diagnosis of "Hürthle-cell neoplasm/follicular neoplasm with oncocytic features" denote increased risk of malignancy? Diagn Cytopathol 31:307-312.

8. Pu RT, Yang J, Wasserman PG, Bhuiya T, Griffith KA, Michael CW 2006 Does Hürthle cell lesion/neoplasm predict malignancy more than follicular lesion/neoplasm on thyroid fine-needle aspiration? Diagn Cytopathol 34:330-334.

9. Sippel RS, Elaraj DM, Khanafshar E, Zarnegar R, Kebebew E, Duh QY, Clark OH 2008 Tumor size predicts malignant potential in Hürthle cell neoplasms of the thyroid. World J Surg 32:702-707.

10. Wu HH, Clouse J, Ren R 2008 Fine-needle aspiration cytology of Hürthle cell carcinoma of the thyroid. Diagn Cytopathol 36:149-154.

11. Renshaw AA 2002 Hürthle cell carcinoma is a better gold standard than Hürthle cell neoplasm for fine-needle aspiration of the thyroid: defining more consistent and specific cytologic criteria. Cancer 96:261-266.

12. Alaedeen DI, Khiyami A, McHenry CR 2005 Fine-needle aspiration biopsy specimen with a predominance of Hürthle cells: a dilemma in the management of nodular thyroid disease. Surgery 138:650-656; discussion 656-657.

13. Ongphiphadhanakul B, Rajatanavin R, Chiemchanya S, Chailurkit L, Kongsuksai A, Isarangkul Na Ayuthya WI 1992 Systematic inclusion of clinical and laboratory data improves diagnostic accuracy of fine-needle aspiration biopsy in solitary thyroid nodules. Acta Endocrinol (Copenh) 126:233-237.

14. Elliott DD, Pitman MB, Bloom L, Faquin WC 2006 Fineneedle aspiration biopsy of Hürthle cell lesions of the thyroid gland: a cytomorphologic study of 139 cases with statistical analysis. Cancer 108:102-109.

15. LiVolsi VA 1990 Surgical Pathology of the Thyroid. WB Saunders, Philadelphia.

16. Obuchowski NA 2003 Receiver operating characteristic curves and their use in radiology. Radiology 229:3-8.

17. Grube E, Bootsveld A, Yuecel S, Shen JT, Imhoff M 2007 Computerized two-lead resting ECG analysis for the detection of coronary artery stenosis. Int J Med Sci 4:249-263.

18. Schisterman EF, Perkins NJ, Liu A, Bondell H 2005 Optimal cut-point and its corresponding Youden Index to discrimi- nate individuals using pooled blood samples. Epidemiology 16:73-81.

19. Hosmer DW, Hosmer T, Le Cessie S, Lemeshow S 1997 A comparison of goodness-of-fit tests for the logistic regression model. Stat Med 16:965-980.

20. Moon WJ, Jung SL, Lee JH, Na DG, Baek JH, Lee YH, Kim J, Kim HS, Byun JS, Lee DH 2008 Benign and malignant thyroid nodules: US differentiation-multicenter retrospective study. Radiology 247:762-770.

21. Hedinger CWE, Sobin LH 1988 WHO. Histologic Typing of Thyroid Tumors. Springer-Verlag, New York.

22. Pisanu A, Sias L, Uccheddu A 2004 Factors predicting malignancy of Hürthle cell tumors of the thyroid: influence on surgical treatment. World J Surg 28:761-765.

23. Chen H, Nicol TL, Zeiger MA, Dooley WC, Ladenson PW, Cooper DS, Ringel M, Parkerson S, Allo M, Udelsman R 1998 Hürthle cell neoplasms of the thyroid: are there factors predictive of malignancy? Ann Surg 227:542-546.

24. Apel RL, Asa SL, LiVolsi VA 1995 Papillary Hürthle cell carcinoma with lymphocytic stroma. "Warthin-like tumor" of the thyroid. Am J Surg Pathol 19:810-814.

25. McHenry CR, Thomas SR, Slusarczyk SJ, Khiyami A 1999 Follicular or Hürthle cell neoplasm of the thyroid: can clinical factors be used to predict carcinoma and determine extent of thyroidectomy? Surgery 126:798-802; discussion 802-804.

26. Arganini M, Behar R, Wu TC, Straus F 2nd, McCormick M, DeGroot LJ, Kaplan EL 1986 Hürthle cell tumors: a twentyfive-year experience. Surgery 100:1108-1115.

27. Tuttle RM, Lemar H, Burch HB 1998 Clinical features associated with an increased risk of thyroid malignancy in patients with follicular neoplasia by fine-needle aspiration. Thyroid 8:377-383.

28. Yang GC, Goldberg JD, Ye PX 2003 Risk of malignancy in follicular neoplasms without nuclear atypia: statistical analysis of 397 thyroidectomies. Endocr Pract 9:510-516.

29. Faraggi D, Simon R 1996 A simulation study of crossvalidation for selecting an optimal cutpoint in univariate survival analysis. Stat Med 15:2203-2213.

Address correspondence to:

Bo Youn Cho, M.D., Ph.D.

Department of Internal Medicine Seoul National University College of Medicine 28 Yongon-Dong Chongno-Gu Seoul 110-744

Korea

E-mail: bycho@snu.ac.kr 
This article has been cited by:

1. Jung Uee Lee, Minho Shong. 2010. Postoperative Findings of the Cytological Diagnosis of Follicular Neoplasm or Hürthle Cell Neoplasm and Risk of Malignancy. Endocrinology and Metabolism 25:4, 298. [CrossRef] 